\title{
Third Portion of the Duodenum
}

National Cancer Institute

\section{Source}

National Cancer Institute. Third Portion of the Duodenum. NCI Thesaurus. Code C33765.

The horizontal portion of the duodenum between the inferior duodenal flexure and the aorta. 